\title{
Effect of No-Reflow/Reflow on P-Wave Time Indexes in Patients with Acute Myocardial Infarction Undergoing Percutaneous Coronary Intervention
}

\author{
Ahmet Karakurt, Cennet Yildiz'1 Doğan Iliş \\ Department of Cardiology, Faculty of Medicine, Kafkas University, Kars, ${ }^{1}$ Department of Cardiology, Bağcilar Tekden Hospital, İstanbul, Turkey \\ ORCID: \\ Ahmet Karakurt: https://orcid.org/0000-0001-8877-100X \\ Cennet Yildiz: https://orcid.org/0000-0003-2456-3206 \\ Doğan lliş: https://orcid.org/0000-0002-1871-5157
}

\section{Abstract}

\begin{abstract}
Aim: The aim of this study was to investigate the relationship between no-reflow (no-RF), reflow (RF), and the P-wave time index in patients undergoing percutaneous coronary intervention (PCI) with a diagnosis of acute myocardial infarction (AMI) due to total occlusion. Methods: This study included a total of 272 AMI patients with no-RF (110 patients) and RF (162 patients). Results: The no-RF group had higher values of mean maxPWT postPCI $(94.95 \pm 15.61$ vs. $117.86 \pm 12.06, P<0.001), \operatorname{minPWT}_{\text {postPCI }}(54.21 \pm 12.13$ vs. $67.31 \pm 11.79, P<0.001)$, and $\mathrm{PWD}{ }_{\mathrm{postPCI}}(39.14 \pm 12.55$ vs. $50.91 \pm 11.9, P<0.001)$ during the post-PCI period. According to multivariate logistic regression analysis,

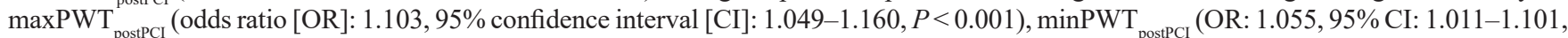
$P=0.0014)$, and PWD ${ }_{\text {postPCI }}(\mathrm{OR}: 1.107,95 \% \mathrm{CI}: 1.037-1.181, P=0.002)$ were the independent predictors of RF after PCI. ROC curve analyses demonstrated that the optimal cutoff values for maxPWT $\mathrm{postPCI}$, minPWT $_{\text {postPCl}}$, and $\mathrm{PWD}_{\text {postPCI }}$ for predicting no-RF were $112.95 \mathrm{~ms}($ area under the curve [AUC]: $0.852,95 \%$ CI: $0.807-0.898, P<0.001$, sensitivity $70 \%$, specificity $85.2 \%$ ), 62.66 ms (AUC: $0.650,95 \%$ CI: $0.585-0.716$, $P<0.001$, sensitivity $54.5 \%$, specificity $72.8 \%$ ), and $43.43 \mathrm{~ms}$ (AUC: $0.782,95 \%$ CI: $0.727-0.837, P<0.001$, sensitivity $75.5 \%$, specificity $60.5 \%$ ), respectively. Conclusions: Prolonged maxPWT ${ }_{\text {postPCI}}$, maxPWT $_{\text {postPCI, }}$ and $\mathrm{PWD}_{\text {postPCI }}$ are independent predictors that differentiate no-RF from RF in patients with AMI after PCI and can be used in the follow-up of no-RF patients during the post-PCI period.
\end{abstract}

Keywords: Acute myocardial infarction, no-reflow, P-wave dispersion, P-wave time, reflow

\section{INTRODUCTION}

Percutaneous coronary intervention (PCI) is the gold standard strategy that exhibits $95 \%$ efficacy in restoring blood flow in the infarct-related coronary artery (IRA); however, myocardial perfusion is still not well corrected in up to $60 \%$ of acute myocardial infarction (AMI) patients. ${ }^{[1-3]}$ Insufficient correction of myocardial perfusion is known as the no-reflow (no-RF) phenomenon, and the etiopathogenesis of this phenomenon is related to persistent microvascular obstruction despite the opening of the IRA with PCI. ${ }^{[4]}$ During no-RF, tissue necrosis continues with its hemodynamic and

\section{Received: 29-10-2019 Revised: 02-01-2020 Accepted: 13-01-2020}

Published Online: 11-06-2020

\begin{tabular}{|l|l|}
\hline \multicolumn{3}{|c|}{ Access this article online } \\
\hline Quick Response Code: & Website: \\
& \\
http:/www.ijcva.com
\end{tabular}

morphological disturbances in both atria and ventricles, resulting in an increased risk of arrhythmia.

Atrial arrhythmias, especially atrial fibrillation, occur during AMI in $5.8 \%$ of cases and are associated with increased mortality and morbidity. ${ }^{[5]}$ Prolonged maximal P-wave time (PWT) and P-wave dispersion (PWD) have been shown as independent predictors of atrial fibrillation

Address for correspondence: Dr. Ahmet Karakurt Department of Cardiology, Faculty of Medicine, Kafkas University, Kars, Turkey. E-mail: karakurt38@hotmail.com

This is an open access journal, and articles are distributed under the terms of the Creative Commons Attribution-NonCommercial-ShareAlike 4.0 License, which allows others to remix, tweak, and build upon the work non-commercially, as long as appropriate credit is given and the new creations are licensed under the identical terms.

For reprints contact: WKHLRPMedknow_reprints@wolterskluwer.com

How to cite this article: Karakurt A, Yildiz C, Iliş D. Effect of no-reflow/ reflow on $\mathrm{P}$-wave time indexes in patients with acute myocardial infarction undergoing percutaneous coronary intervention. Int J Cardiovasc Acad 2020;6:57-65. 
and its associated mortality and morbidity. ${ }^{[6-8]}$ Although a few studies have highlighted the relationship between these parameters and AMI, ${ }^{[9-11]}$ no study has investigated the relationship between $\mathrm{PWT}, \mathrm{PWD}$, and no-RF in addition to PWT, PWD, and reflow (RF) in patients with AMI before and after PCI.

Therefore, the present study aimed to investigate the effects of no-RF and RF on PWT and PWD in groups of AMI patients who underwent PCI with no-RF and RF.

\section{Methods}

\section{Patient population}

This was a retrospective, cross-sectional design and was based on patient files that were conducted between January 2014 and September 2018 at the University Hospital Cardiology Clinic. Between these dates, we scanned stored digital angiographic images of 4532 patients with AMI and reevaluated the angiographic images of patients with no-RF (no-RF group, $n$ : 110). The RF patients were randomly selected from stored digital angiographic images of 4532 patients with reflow (RF group, $n$ : 162). No-RF and RF were determined depending on their myocardial blush grade (MBG). The study started after obtaining written approval from the local ethics board, and the research protocol was as per the Declaration of Helsinki (ID: 80576354-050-99/108).

The inclusion criteria were as follows: total or subtotal occlusion of the IRA in AMI patients and postprocedural MBG $0-1$ for no-RF patients and 3 for RF patients (Grade $0=$ contrast density absent in the myocardium; Grade $1=$ contrast density minimal in the myocardium; Grade $2=$ contrast density moderate in the myocardium but less than that obtained from the ipsilateral non-IRA; and Grade 3 = normal contrast density in myocardium present during angiography). ${ }^{[12]}$

The excluded criteria were as follows: (1) patients with stable or unstable angina who had undergone PCI or had previous coronary artery bypass surgery history; (2) antiarrhythmic medicine usage; (3) valve disease; (4) constrictive/restrictive myocarditis, pericarditis, pericardial effusion, or cardiac tamponed; (5) electrolyte imbalance; (6) morbid obesity; (7) hypo-/hyperthyroidism; (8) chronic obstructive lung disease or secondary pulmonary hypertension (HT); (9) chronic renal or hepatic insufficiency; (10) pace rhythm or bundle branch block; and (11) an uncertain beginning or end of P-wave on a 12-lead electrocardiography (ECG).

\section{Percutaneous coronary intervention variables}

The PCI was performed through femoral access using conventional angiographic views. We stored all images obtained during the procedure were stored in a digital format. Stored images were reevaluated again, and we divided the study patients into the no-RF or the RF group depending on their MBG. Syntax scores (SS) (using an online calculator, http:/www.syntaxscore.com/calculator/ start.htm) and thrombolysis in acute myocardial infarction thrombus grade (TIMI-TG) $(0=$ no thrombus; $1=$ hazy, possible thrombus present; $2=$ thrombus present - small size [greatest dimensions $\leq 1 / 2$ vessel diameter]; $3=$ thrombus present - moderate size [linear dimension $>1 / 2$ but $<2$ vessel diameters]; $4=$ thrombus present - large size [largest dimension $\geq 2$ vessel diameters]; 5 = recent total occlusion; and $6=$ chronic total occlusion) of the patients were calculated from the stored angiographic images.

\section{Electrocardiography variables}

ImageJ software (https://imagej.net/Downloads) was used for scanning and analyzing the electrocardiogram (ECG) of the patients. All of the ECGs were calibrated at $5 \mathrm{~mm}$, which represented $200 \mathrm{~ms}$ maxPWT was measured in leads II and aVF, and the longest measurement was accepted as maxPWT. Likewise, minPWT was measured in leads aVL and V1, and the shortest measurement was accepted as minPWT. MaxPWT and minPWT were the longest and shortest measurements obtained in leads II or aVF, respectively. All measurements were made manually with a magnifying glass that had a magnifying power of 900-1200 times. We described atrial deflection from the isoelectric line as the beginning and the end of the P-wave. MaxPWT and minPWT were measured for all the patients. Preprocedural PWD ( $\mathrm{PWD}_{\text {prePCr) }}$ and postprocedural PWD ( PWD $_{\text {postPCI }}$ ) were described as the difference between preprocedural maxPWT and minPWT and postprocedural maxPWT and minPWT, respectively. MaxPWD and minPWD wave measurements corrected for heart rate (i.e., the corrected $\mathrm{P}$-wave parameters were equal to $\mathrm{P}$-wave parameters/(RR) $1 / 2$. ${ }^{[13]}$ The maximum ST-elevation was measured from the lead, which exhibited the highest ST elevation, before and after PCI. The formula for the degree of ST-segment resolution (\%STER) was: $\left[\left(\operatorname{maxSTE}_{\text {prePCI}}-\operatorname{minSTE}_{\text {postPCI }}\right) / \operatorname{maxSTE}{ }_{\text {prePCI }} \times 100\right]$. Meanwhile, the number and percentage of the patients who showed $50 \%$ and $70 \%$ of ST-segment resolution were calculated. We evaluated all the atrial arrhythmias developed during the hospital stay from patients' follow-up ECG, monitor records, or cardiologist follow-up notes.

\section{Statistical analysis}

The statistical analyses were performed using SPSS 21.00 package software (SPSS, Inc., Chicago, Illinois, USA). The scale data were interpreted as parametric distribution data if the Skewness/Std. Error and Kurtosis/Std. Error ratio was within the range of \pm 1.96 . Nominal and ordinal data were evaluated with a Chi-square test, and all variables were presented as absolute values and percentages. Parametric data were compared between and within the groups using a Student's $t$-test and paired sample $t$-test, respectively. Nonparametric data were compared between and within the groups using a Mann-Whitney U-test and Wilcoxon signed-rank test, respectively. Scale parametric variables were reported as the mean value \pm standard deviation, and scale nonparametric variables were reported as the median value $\left(25^{\text {th }}-75^{\text {th }}\right.$ percentile $) . P<0.05$ was considered significant. A receiver operating characteristic (ROC) curve analysis was used for determining the cutoff value, sensitivity, and specificity of PWT, and PWD, respectively. 


\section{RESULTS}

We expressed the clinical characteristics and biochemical parameters of the no-RF and RF groups in Table 1. Of 4532 patients with AMI undergoing PCI, 110 (2.43\%) developed no-RF. The no-RF and RF groups consisted of 70.9/29.1\% (78/32) males/females and 77.8/22.2\% (126/36) males/females, respectively $(P=0.199)$. The mean age of no-RF and RF groups was $67.18 \pm 11.81$ and $63.57 \pm 2.55$ years, respectively $(P=0.018)$.

We found no significant differences in HT, hyperlipidemia, and family history between the two groups $(P=0.117, P=0.076$, $P=0.366$, respectively); however, body mass index, diabetes mellitus, and smoking were significantly higher in the no-RF group ( $P<0.001, P<0.001, P=0.030$, respectively). The no-RF group also had a higher length of hospital and coronary care unit stay $(P<0.001$ for both $)$.

Preprocedural heart rate $\left(\mathrm{HR}_{\text {prePCI }}\right)$, systolic blood pressure, diastolic blood pressure, and pulse pressure showed no significant difference between the two groups $(P=0.469$, $P=0.416, P=0.067, P=0.146$, respectively). The postprocedural heart rate $\left(\mathrm{HR}_{\text {postPCI }}\right)$ of the no-RF patients was significantly higher than that of the RF patients $(P<0.001)$.
We detected 44 atrial arrhythmias (1.6\%) in the study population during inhospital follow-up, 29 of which (29\%) were in the no-RF group and 15 of which $(9.3 \%)$ were in the RF group. Moreover, the rate of atrial arrhythmia observed in the no-RF group was higher than in the RF group $(P<0.001)$. Furthermore, we observed 15 atrial fibrillations (13.6\%) in the no-RF group, and this rate was higher than the whole of the RF $(5.6 \%)$ group $(P=0.028)$. Moreover, correlation analysis showed a significant correlation between atrial

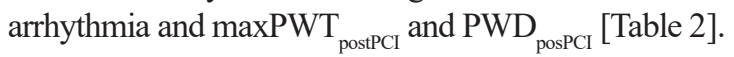

There was no significant difference between the two groups in terms of drug medication ( $\beta$-blocker, $\mathrm{Ca}^{2+}$-blockers, amiodarone, angiotensin-converting enzyme inhibitors, angiotensin receptor blocker, diuretics, nitrates, and H2-receptor blocker).

Nine patient deaths were recorded, and this rate was higher in the no-RF group $(6.36 \%)$ than the RF group $(1.24 \%)(P=0.033)$.

Postprocedural left atrial posteroanterior diameter $\left(\mathrm{LAD}_{\text {postPCI }}\right)$, left ventricular diastolic diameter $\left(\mathrm{LVEDD}_{\text {postPCI }}\right)$, left ventricular systolic diameter $\left(\operatorname{LVESD}_{\text {postPCI}}\right)$, and left ventricular ejection fraction $\left(\mathrm{LVEF}_{\text {postPCI}}\right)$ showed a significant difference

Table 1: The demographic, clinical, biochemical, and echocardiographic characteristics of patients with no-reflow and reflow groups and with the $P$ value

\begin{tabular}{|c|c|c|c|c|}
\hline & Overall $(n=272)$ & No-RF group $(n=10)$ & RF group ( $n=162$ ) & $P$ \\
\hline Age (years) & $65.03 \pm 12.36$ & $67.18 \pm 11.81$ & $63.57 \pm 2.55$ & 0.018 \\
\hline Male gender & $40.4 \%(110)$ & $70.9 \%(78)$ & $77.8 \%(126)$ & 0.199 \\
\hline BMI $\left(\mathrm{kg} / \mathrm{m}^{2}\right)$ & $29.8(28.1-32.9)$ & $30.5(28.5-34.8)$ & $29.1(27.6-31.9)$ & $<0.001 *$ \\
\hline Hypertension & $48.2 \%(131)$ & $52.7 \%(58)$ & $45.1 \%(73)$ & 0.117 \\
\hline Diabetes mellitus & $30.5 \%(83)$ & $44.6 \%(49)$ & $20.7 \%(34)$ & $<0.001$ \\
\hline Smoker & $33.8 \%(139)$ & $58.2 \%(64)$ & $46.3 \%(75)$ & 0.030 \\
\hline Dyslipidemia & $33.8 \%(92)$ & $39.1 \%(43)$ & $30.2 \%(49)$ & 0.076 \\
\hline Family history & $22.8 \%(62)$ & $21 \%(34)$ & $25.7 \%(28)$ & 0.366 \\
\hline \multicolumn{5}{|l|}{ HR (bpm) } \\
\hline Pre-PCI & $72.5(65-83)$ & $72(68-83)$ & $74(61-83)$ & $0.469^{*}$ \\
\hline Post-PCI & $74.1(68-79)$ & $76(71-88)$ & $73(64-76)$ & $<0.001 *$ \\
\hline \multicolumn{5}{|l|}{ Blood pressure (mmHg) } \\
\hline SBP & $137(124-154)$ & $138(128.3-148.3)$ & $123(115-156)$ & $0.416^{*}$ \\
\hline DBP & $91(78-99)$ & $93(81-99)$ & $90.5(73.3-102)$ & $0.067 *$ \\
\hline Pulse pressure & $49.89 \pm 10.96$ & $48.72 \pm 10.76$ & $50.7 \pm 11.6$ & 0.146 \\
\hline \multicolumn{5}{|c|}{ Peak cardiac enzymes (ng/mL) } \\
\hline CK-MB & $195.6(108.4-310.9)$ & $261(195.4-349.2)$ & $140.5(98-256.5)$ & $<0.001 *$ \\
\hline Troponin-I & $26.5(25-67.75)$ & $59(46.5-80)$ & $25(18-26)$ & $<0.001 *$ \\
\hline \multicolumn{5}{|l|}{ Echocardiography } \\
\hline $\mathrm{LAD}_{\text {postPCI }}(\mathrm{mm})$ & $38.45 \pm 2.88$ & $39.72 \pm 2.22$ & $37.57 \pm 2.96$ & $<0.001$ \\
\hline LVEDD $_{\text {postPCI }}(\mathrm{mm})$ & $47.69 \pm 2.73$ & $48.11 \pm 3.28$ & $47.4 \pm 2.25$ & 0.044 \\
\hline $\operatorname{LVESD}_{\text {postPCI }}(\mathrm{mm})$ & $34.91 \pm 2.23$ & $35.6 \pm 2.08$ & $34.43 \pm 2.22$ & $<0.001$ \\
\hline $\operatorname{LVEF}_{\text {postPCI }}(\%)$ & $47.21 \pm 7.43$ & $44.24 \pm 8.35$ & $49.26 \pm 5.93$ & $<0.001$ \\
\hline \multicolumn{5}{|l|}{ Hospital stay (days) } \\
\hline Coronary care stay & $2.7 \pm 1.58$ & $3.23 \pm 1.65$ & $2.29 \pm 1.45$ & $<0.001$ \\
\hline Cardiology clinic stay & 6.312 .7 & $7.14 \pm 2.92$ & $5.77 \pm 2.41$ & $<0.001$ \\
\hline
\end{tabular}


between the two groups ( $P<0.001, P=0.044, P<0.001$, and $P<0.001$, respectively).

The preprocedural and postprocedural PWT indexes of the patients are shown in Table 3. MaxPWT ${ }_{\text {prePCI }}$ and maxPWD ${ }_{\text {postPCI }}$ of the no-RF and RF groups were $119.08 \pm 16.85 \mathrm{~ms}$ versus $118.04 \pm 20.09 \mathrm{~ms}(P=0.656)$ and $117.86 \pm 12.06 \mathrm{~ms}$ versus $94.95 \pm 15.61(P<0.001)$, respectively. The minPWT prePCI $_{\text {and }}$ $\operatorname{minPWT}_{\text {postPCI }}$ of the no-RF and RF groups were $67.54 \pm 14.66$ $\mathrm{ms}$ versus $70.02 \pm 15.5 \mathrm{~ms}(P=0.187)$ and $67.31 \pm 11.79 \mathrm{~ms}$ versus $54.21 \pm 12.13 \mathrm{~ms}(P<0.001)$, respectively.

The no-RF group had higher values of $\mathrm{PWD}_{\text {prePCI }}$ and $\mathrm{PWD}_{\text {postPCI }}$ when compared to the RF group (51.54 $\pm 17.11 \mathrm{~ms}$ vs. $48.02 \pm 19.36, P=0.125$, and $50.91 \pm 11.9 \mathrm{~ms}$ vs. $39.14 \pm 12.55$ $\mathrm{ms}, P<0.001$, respectively). Although the preprocedural mean PWD did not exhibit a statistically significant difference, the postprocedural mean PWD was significantly higher in the no-RF group than the RF group.

Pairwise comparisons of $0,1,2$, and $3 \mathrm{MBG}$ subgroups with PWT indices are shown in Table 4. We did not observe significant differences regarding $\operatorname{maxPWT}_{\text {prePCI}}, \operatorname{minPWT}_{\text {prePCI}}$, and $\mathrm{PWD}_{\text {prePCI }}$ between MBG subgroups during pre-PCI period. However, we observed significant differences in some PWT indices during post-PCI period. The differences were as follows: (1) mean difference of maxPWT ${ }_{\text {postPCI }}$ between MBG 0 and 2, 0 and 3,1 and 2, 1 and 3, 2 and 3 (all $P<0.01$ ); (2)

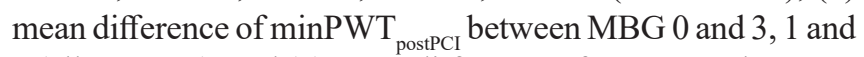
3 (all $P<0.05$ ); and (3) mean difference of PWD ${ }_{\text {postPCI }}$ between MBG 0 and 2, 0 and 3, 1 and 3 (all $P<0.001$ ).

The mean of the preprocedural maximum ST-segment elevation ( $\operatorname{maxSTE}_{\text {prePCI}}$ ) was not statistically significantly different between the no-RF group and RF group (6.13 $\pm 3.2 \mathrm{vs.}$ $6.5 \pm 2.99, P=0.333$ ); however, the mean of the postprocedural maximum ST-segment elevation ( $\operatorname{maxSTED}_{\text {postPCI}}$ ) was significantly higher in the no-RF group than the RF group ( $4.16 \pm 2.29$ vs. $2.56 \pm 1.55, P<0.001)$. Similarly, the percentage of patients who exhibited $70 \%$ and $50 \%$ ST-segment resolutions (STSR) was lower in the no-RF group than the RF group (4.5\% vs. $34.6 \%, P<0.001$, and $23.6 \%$ vs. $66 \%, P<0.001$, respectively). The no-RF group did not show any significant differences in maxPWT and minPWT ve PWD values before and after PCI, whereas these parameters decreased after PCI in the RF group.

The mean stent length, TIMI-TG, and SS of the no-RF patients were significantly higher than those of the RF group; however, stent diameter, TIMI-MBG ${ }_{\text {prePCI}}$, and TIMI-MBG ${ }_{\text {postPCI }}$ were significantly lower than those of the RF group.

The no-RF group showed a meaningful correlation with $\mathrm{HR}_{\text {postPCI}}$, maxPWT ${ }_{\text {postPCI}}, \operatorname{minPWT}_{\text {postPCI}}$, and $\mathrm{PWD}_{\text {postPCI}}$. Although there was no correlation between TIMI-TG and $\operatorname{minPWT}_{\text {postPCI}}, \% \mathrm{STER}, \mathrm{HR}_{\text {prePCI}}, \operatorname{maxPWT}_{\text {prePCI}}$, $\operatorname{minPWT}_{\text {prePCI}}$, and PWD prePCI , TIMI-TG and \%STER exhibited a meaningful correlation with $\mathrm{HR}_{\text {postPCI}}$, $\operatorname{maxPWT}_{\text {postPCI}}, \operatorname{minPWT}_{\text {postPCI}}, \operatorname{minPWT}_{\text {postPCI, }}$ and $\mathrm{PWD}_{\text {postPCl}}$ Furthermore, the atrial arrhythmias showed a significant correlation with maxPWT ${ }_{\text {postPCI }}$ and $\mathrm{PWD}_{\text {postPCI}}$. Correlation analyses of the parameters are shown in Table 2, and

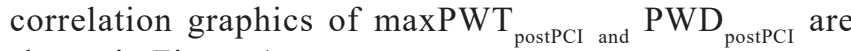
shown in Figure 1.

The univariate logistic regression analysis showed that maxPWT $_{\text {postPCI }}$ (odds ratio $[\mathrm{OR}]=0.1 .105,95 \%$ confidence interval $[\mathrm{CI}]: 0.1 .078-1.133, P<0.001)$, $\operatorname{minPWT}_{\text {postPCI }}(\mathrm{OR}=1.035, \mathrm{CI}: 1.015-1.054, P<0.001)$, and $\mathrm{PWD}_{\text {postPCI }}(\mathrm{OR}=1.106, \mathrm{CI}: 1.076-1.137, P<0.001)$ were absolute predictors of the no-RF. This analysis displayed that $\operatorname{maxPWT}_{\text {postPCI}}, \operatorname{minPWT}_{\text {postPCI}}$, and maxPWT $\mathrm{PostPCI}_{\text {were the }}$ predictors of the no-RF [Table 5]. According to multivariate logistic regression analysis-entered models, including STER, peak troponin-I, TIMI-TG, $\mathrm{MBG}_{\text {postPCI}}$, IRA, and three coronary disease, maxPWT ${ }_{\text {postPCI }}(\mathrm{OR}: 1.103,95 \% \mathrm{CI}$ : 1.049-1.16, $P<0.001$ ), minPWT ${ }_{\text {postPCI }}$ (OR: $1.055,95 \% \mathrm{CI}$ : 1.011-1.101, $P<0.014$ ), and PWD ${ }_{\text {postPCI }}(\mathrm{OR}: 1.107,95 \% \mathrm{CI}$ : 1.037-1.181, $P=0.002$ ) were the independent predictors of no-RF after PCI.

The ROC curve analyses demonstrated that the optimal

Table 2: Correlation analysis between P-wave time index and no-reflow, percentage ST-elevation resolution, thrombolysis in acute myocardial infarction-thrombus grade, and syntax score

\begin{tabular}{|c|c|c|c|c|c|c|c|c|c|c|}
\hline & \multicolumn{2}{|c|}{ No-RF } & \multicolumn{2}{|c|}{ Atrial arrhythmias } & \multicolumn{2}{|c|}{ \%STER } & \multicolumn{2}{|c|}{ TIMI-TG } & \multicolumn{2}{|c|}{ Syntax score } \\
\hline & $r$ & $P$ & $r$ & $P$ & $r$ & $P$ & $r$ & $P$ & $r$ & $P$ \\
\hline $\mathrm{HR}_{\mathrm{prePCI}}$ & 0.033 & 0.590 & -0.019 & 759 & -0.010 & 0.872 & 0.205 & 0.001 & 0.039 & 0.523 \\
\hline $\mathrm{HR}_{\text {postPCI }}$ & 0.277 & $<0.001$ & 116 & 0.060 & -0.125 & 0.039 & 0.235 & $<0.001$ & 0.207 & $<0.001$ \\
\hline MaxPWT $_{\text {prePCI }}$ & 0.020 & 0.742 & 047 & 0.439 & -0.027 & 0.652 & 0.259 & $<0.001$ & 0.196 & 0.001 \\
\hline MaxPWT $_{\text {postPCI }}$ & 0.571 & $<0.001$ & 0.223 & $<0.001$ & -0.329 & $<0.001$ & 0.203 & 0.001 & 0.313 & $<0.001$ \\
\hline MinPWT $_{\text {prePCI }}$ & -0.016 & 0.793 & -059 & 0.335 & 0.025 & 0.676 & -0.202 & 0.001 & 0.055 & 0.363 \\
\hline MinPWT $_{\text {postPCI }}$ & 0.219 & $<0.001$ & -0.110 & 0.069 & -0.181 & $<0.003$ & -0.049 & 0.422 & 0.103 & 0.090 \\
\hline $\mathrm{PWD}_{\text {prePCI }}$ & 0.034 & 0.579 & 0.097 & 0.112 & -0.049 & 0.419 & 0.433 & $<0.001$ & 0.158 & 0.009 \\
\hline $\mathrm{PWD}_{\text {postPCI }}$ & 0.545 & $<0.001$ & 0.385 & $<0.001$ & -0.239 & $<0.001$ & 0.300 & $<0.001$ & 0.293 & $<0.001$ \\
\hline
\end{tabular}

HR: Heart rate, MaxPWT: Maximum P-wave time, minPWT: Minimum P-wave time, post-PCI: Postpercutaneous coronary intervention, pre-PCI: Prepercutaneous coronary intervention, PWD: P-wave dispersion, TIMI-TG: Thrombolysis in acute myocardial infarction thrombus grade, RF: Reflow, STER: ST-elevation resolution 
Table 3: Comparison of maximal P-wave time, minimal P-wave time, P-wave dispersion values, and other parameters between no-reflow and reflow groups before and after percutaneous coronary intervention and with the $P$ value

\begin{tabular}{|c|c|c|c|c|}
\hline & Overall $(n=272)$ & No-RF group $(n=110)$ & RF group $(n=162)$ & $P$ \\
\hline $\operatorname{MaxPWT}_{\text {prePCI }}(\mathrm{ms})$ & $118.56 \pm 19.08$ & $119.08 \pm 16.85$ & $118.04 \pm 20.09$ & 0.656 \\
\hline $\operatorname{MaxPWT}_{\text {postPCI }}(\mathrm{ms})$ & $105.56 \pm 17.8$ & $117.86 \pm 12.06$ & $94.95 \pm 15.61$ & $<0.001$ \\
\hline $\operatorname{MinPWT}_{\text {prePCI }}(\mathrm{ms})$ & $67.92 \pm 15.06$ & $67.54 \pm 14.66$ & $70.02 \pm 15.5$ & 0.187 \\
\hline $\operatorname{MinPWT}_{\text {postPCI }}(\mathrm{ms})$ & $60.46 \pm 13.64$ & $67.31 \pm 11.79$ & $54.21 \pm 12.13$ & $<0.001$ \\
\hline $\mathrm{PWD}_{\mathrm{prePCI}}(\mathrm{ms})$ & $50.63 \pm 18.46$ & $51.54 \pm 17.11$ & $48.02 \pm 19.36$ & 0.125 \\
\hline $\mathrm{PWD}_{\text {postPCI }}(\mathrm{ms})$ & $45.11 \pm 14.25$ & $50.91 \pm 11.9$ & $39.14 \pm 12.55$ & $<0.001$ \\
\hline $\operatorname{MaxSTE}_{\text {prePCI }}(\mathrm{mm})$ & $6.35 \pm 3.07$ & $6.13 \pm 3.2$ & $6.5 \pm 2.99$ & 0.333 \\
\hline $\operatorname{MaxSTE}_{\mathrm{postPCI}}(\mathrm{mm})$ & $3.21 \pm 2.03$ & $4.16 \pm 2.29$ & $2.56 \pm 1.55$ & $<0.001$ \\
\hline MaxSTER $(\%)$ & $45.52 \pm 26.7$ & $27.9 \pm 22.95$ & $58.14 \pm 21.66$ & $<0.001$ \\
\hline $\operatorname{MaxSTER}(\geq 70 \%)$ & $22.4 \%(61)$ & $4.5 \%(5)$ & $34.6 \%(56)$ & $<0.001$ \\
\hline MaxSTER ( $\geq 50 \%)$ & $48.9 \%(133)$ & $23.6 \%(26)$ & $66 \%(107)$ & $<0.001$ \\
\hline \multicolumn{5}{|l|}{ Atrial arrhythmias } \\
\hline $\mathrm{AF}$ & $8.8 \%(24)$ & $13.6 \%(15)$ & $5.6 \%(9)$ & 0.028 \\
\hline All atrial arrhythmias & $16.2 \%(44)$ & $26.4 \%(29)$ & $9.3 \%(15)$ & $<0.001$ \\
\hline \multicolumn{5}{|l|}{ Drug therapy } \\
\hline$\beta$-blocker & $53.7 \%(146)$ & $60.9 \%(67)$ & $48.8 \%(79)$ & 0.063 \\
\hline $\mathrm{Ca}^{2+}$-blockers & $7.7 \%(20)$ & $8.2 \%(9)$ & $6.8 \%(11)$ & 0.644 \\
\hline Amiodarone & $2.9 \%(8)$ & $1.8 \%(2)$ & $3.7 \%(6)$ & 0.480 \\
\hline ACE inhibitors & $34.9 \%(95)$ & $35.5 \%(39)$ & $34.6 \%(56)$ & 0.897 \\
\hline $\mathrm{ARB}$ & $18.8 \%(51)$ & $20.0 \%(22)$ & $17.9 \%(29)$ & 0.752 \\
\hline Diuretics & $7.7 \%(21)$ & $10.9 \%(12)$ & $5.6 \%(9)$ & 0.112 \\
\hline Nitrates & $7.7 \%(21)$ & $10.0 \%(11)$ & $6.2 \%(10)$ & 0.256 \\
\hline H2-receptor blocker & $\%(195)$ & $66.4 \%(73)$ & $75.3 \%(122)$ & 0.131 \\
\hline \multicolumn{5}{|l|}{ IRA } \\
\hline LAD & $71.7 \%(104)$ & $30.9 \%(50)$ & $49.1 \%(54)$ & 0.005 \\
\hline $\mathrm{CX}$ & $7.4 \%(20)$ & $11.7 \%(19)$ & $10 \%(11)$ & 0.591 \\
\hline RCA & $45.6 \%(124)$ & $54.9 \%(89)$ & $31.8 \%(35)$ & 0.001 \\
\hline $\mathrm{HL}$ & $5.2 \%(14)$ & $11.7 \%(4)$ & $9.1 \%(10)$ & 0.015 \\
\hline \multicolumn{5}{|l|}{ Coronary critical lesions } \\
\hline One coronary & $29.8 \%(81)$ & $14.5 \%(16)$ & $40.1 \%(65)$ & $<0.001$ \\
\hline Two coronary & $53.3 \%(145)$ & $58.2 \%(64)$ & $50.0 \%(81)$ & 0.184 \\
\hline Three coronary & $16.5 \%(46)$ & $9.9 \%(16)$ & $27.3 \%(30)$ & $<0.001$ \\
\hline CTO present & $5.5 \%(15)$ & $10.9 \%(12)$ & $1.9 \%(3)$ & 0.002 \\
\hline \multicolumn{5}{|l|}{ Stent number } \\
\hline One stent & $84.2 \%(229)$ & $81.8 \%(90)$ & $85.7 \%(139)$ & 0.377 \\
\hline Two stent & $12.9 \%(35)$ & $13.6 \%(15)$ & $12.4 \%(20)$ & 0.755 \\
\hline Three stent & $2.9 \%(8)$ & $4.5 \%(5)$ & $1.9 \%(3)$ & 0.197 \\
\hline Stent diameter $(\mathrm{mm})$ & $2.95 \pm 0.43$ & $2.82 \pm 0.32$ & $3.04 \pm 0.48$ & $<0.001$ \\
\hline Stent length (mm) & $23.99 \pm 7.09$ & $26.17 \pm 7.29$ & $22.5 \pm 6.59$ & $<0.001$ \\
\hline TIMI-TG & $3.08 \pm 1.07$ & $3.43 \pm 0.87$ & $2.85 \pm 1.12$ & $<0.001$ \\
\hline TIMI-MBG $\mathrm{prePCI}$ & $0.121 \pm 0.359$ & $0.091 \pm 0.319$ & $0.142 \pm 0.384$ & 0.251 \\
\hline TIMI-MBG ${ }_{\text {postPCI }}$ & $1.967 \pm 1.269$ & $0.782 \pm 1.008$ & $2.772 \pm 0.643$ & $<0.001$ \\
\hline Syntax score & $19.66 \pm 7.84$ & $22 \pm 8$ & $16.24 \pm 7.41$ & $<0.001$ \\
\hline Mortality & $3.3 \%(9)$ & $6.36 \%(7)$ & $1.24 \%(2)$ & 0.033 \\
\hline
\end{tabular}

ACE: Angiotensin-converting enzyme inhibitor, AF: Atrial fibrillation, APC: atrial premature contraction, ARB: Angiotensin receptor blocker,

CTO: Chronic total occlusion, Cx: Circumflex, HL: High lateral, LAD: Left anterior descending, maxPWT: Maximal P-wave time, maxSTE: Maximal ST elevation, MBG: Myocardial blush great, minPWT: Minimal P-wave time, post-PCI: Postpercutaneous coronary interventions, pre-PCI: Prepercutaneous coronary intervention, PWD: P-wave dispersion, RCA: Right coronary artery, STER: ST-elevation resolution, TG: Thrombus grade, TIMI: Thrombolysis in acute myocardial infarction, RF: Reflow, IRA: Infarct related artery

cutoff values of maxPWT ${ }_{\text {postPCI }}, \operatorname{minPWT}_{\text {postPCl}}$, and $\mathrm{PWD}_{\text {postPCI }}$ for predicting the no-RF were $112.95 \mathrm{~ms}$ (area under the curve [AUC]: $0.852,95 \%$ CI: $0.807-0.898, P<0.001$, sensitivity $70 \%$, specificity $85.2 \%$ ), $62.66 \mathrm{~ms}$ (AUC: $0.650,95 \%$ CI: $0.585-0.716, P<0.001$, sensitivity $54,5 \%$, specificity $72,8 \%$ ), and $43.43 \mathrm{~ms}$ (AUC: $782,95 \% \mathrm{CI}$ : $0.727-0.837, P<0.001$, sensitivity $75.5 \%$, specificity $60.5 \%)$, respectively [Figure 2]. 


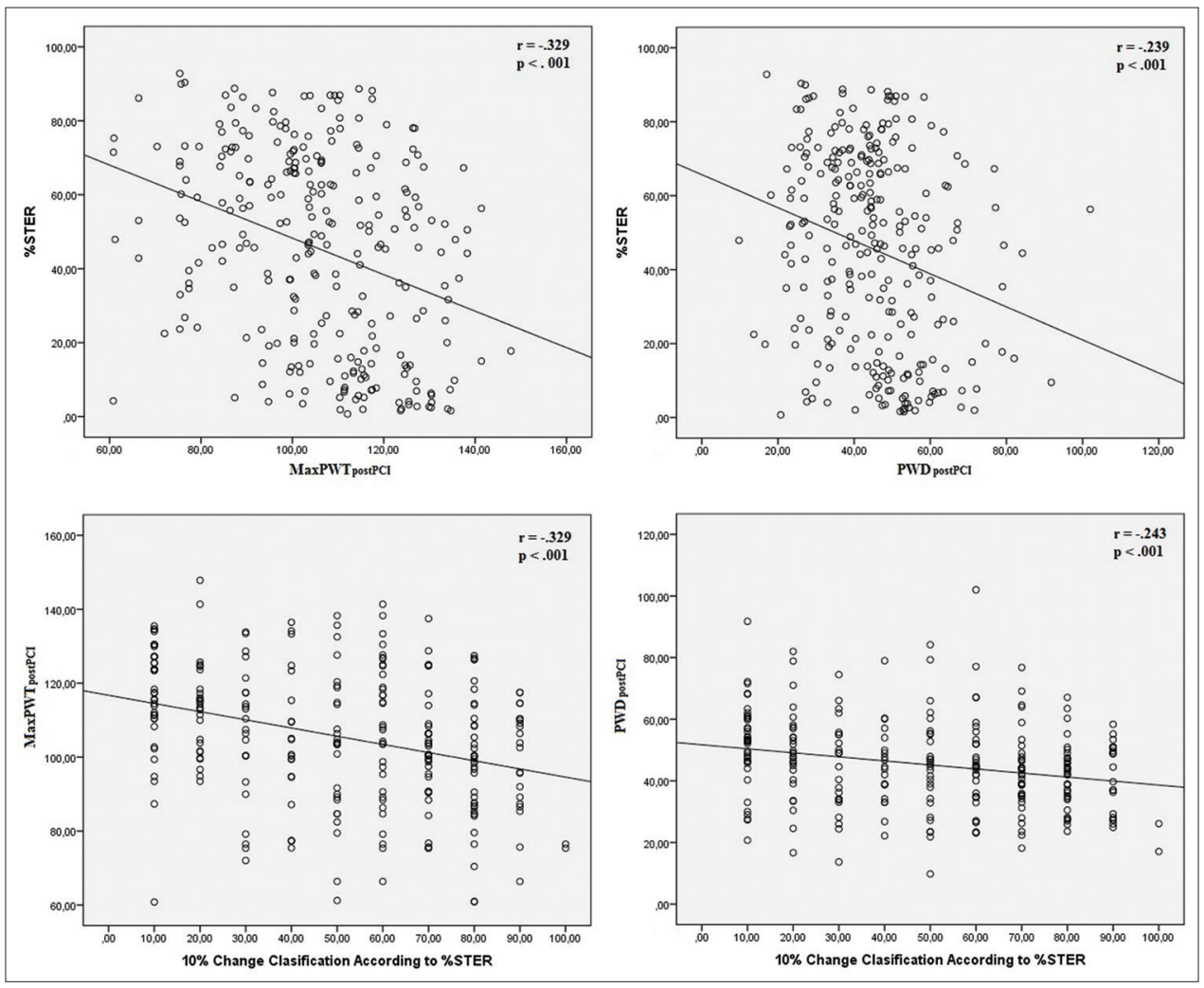

Figure 1: Correlation analysis between maxPWT ${ }_{\text {postPCl}}$, PWD $_{\text {postPCl}}$ \%STER, and the 10\% change classification according to \%STER (a-d). PWD: P-wave dispersion, PWT: P-wave time, STER: ST-elevation resolution

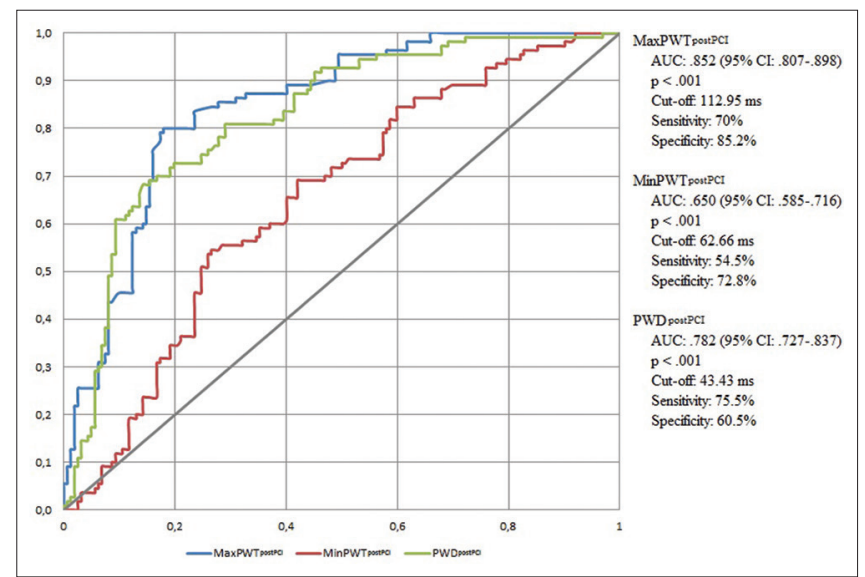

Figure 2: The receiver operating characteristics curves for the $\operatorname{maxPWT}_{\text {postPCl}}$, minPWT ${ }_{\text {postPCl, }}$, and PWD ${ }_{\text {postPCl }}$ values in the prediction of the no-reflow. PWD: P-wave dispersion, PWT: P-wave time, AUC: Area under the curve, $\mathrm{Cl}$ : Confidence interval

\section{Discussion}

The present study revealed the impact of the no-RF/RF on PWT indexes. During the pre-PCI period, maxPWT, minPWT, and PWD were prolonged in both the no-RF and RF groups, whereas, during the post-PCI period, they were shorter in only the RF group. Moreover, maxPWT, minPWT, and PWD correlated with \%STER, TIMI-TG, and coronary artery complexity. These findings suggest that no-RF and RF have favorable adverse effects on P-wave morphology.
No-RF can be defined as impaired tissue circulation and continuing necrosis despite the opening of the IRA with PCI. ${ }^{[4]}$ Distal coronary embolization during PCI (within 0-40 min), which causes microvascular obstruction, an inflammatory response, ischemia (interventional no-RF), and microvascular obstruction caused by prolonged ischemia (after $90 \mathrm{~min}$ ) along with ischemia-reperfusion injury, myocardial edema, endothelial swelling, changes in blood viscosity, capillary obstruction, vasospasm, inflammatory response, and thrombus formation (reperfusion no-RF) are mechanisms suggested as playing a role in the pathogenesis of the no-RF. ${ }^{[14]}$

Regardless of the pathophysiological mechanism, tissue necrosis continues and ischemic/necrotic tissue extends beyond the ischemic area during no-RF. ${ }^{[15]}$ Production of reactive oxygen species (ROS), such as superoxide anion $\left(\mathrm{O}^{2-}\right)$, hydrogen peroxide $\left(\mathrm{H}_{2} \mathrm{O}_{2}\right)$, and hydroxyl radical ( $\left.\mathrm{HO}^{*}\right)$, may lead to some morphological, hemodynamic, and arrhythmogenic effects in the heart. ${ }^{[16-19]}$

Besides tissue degeneration, the presence of too much ROS directly or indirectly causes conduction disorders in atrial and ventricular myocytes, arrhythmias, and a reduction in conduction velocity. ${ }^{[17-19]}$ Experimental studies have shown that ROS promotes arrhythmia formation by lengthening action potential duration, early inducting afterdepolarization, and retarding afterdepolarization. ${ }^{[20]}$ Increased ROS may provide a basis for a re-entry mechanism by making differences in action potential duration in the ischemic myocardium. ${ }^{[21-23]}$ The myocardial effects 


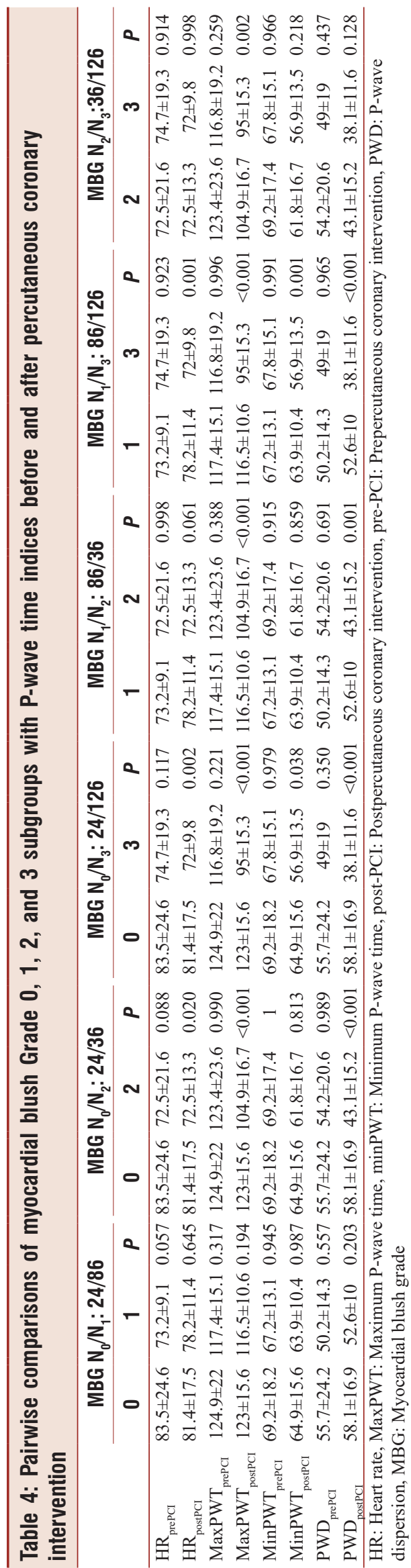

\begin{tabular}{|c|c|c|c|c|c|c|}
\hline \multicolumn{7}{|c|}{$\begin{array}{l}\text { Table 5: The univariate and multivariate logistic } \\
\text { regression analysis of the P-wave time index for } \\
\text { prediction of no-reflow }\end{array}$} \\
\hline & \multirow[t]{2}{*}{$B$} & \multirow[t]{2}{*}{ SE } & \multirow[t]{2}{*}{$P$} & \multirow[t]{2}{*}{ OR } & \multicolumn{2}{|c|}{ 95\% Cl for Exp (B) } \\
\hline & & & & & Lower & Upper \\
\hline \multicolumn{7}{|c|}{ Univariate logistic regression analysis } \\
\hline MaxPWT $_{\text {paspCI }}$ & 0.100 & 0.013 & $<0.001$ & 1.105 & 1.078 & 1.133 \\
\hline MinPWT & 0.030 & 0.010 & $<0.001$ & 1.035 & 1.015 & 1.054 \\
\hline $\mathrm{PWD}_{\text {posipCI }}$ & 0.101 & 0.014 & $<0.001$ & 1.106 & 1.076 & 1.137 \\
\hline \multicolumn{7}{|c|}{ Multivariate logistic regression analysis for the MaxPWTpostPCI } \\
\hline MaxPWT $_{\text {posspCI }}$ & 0.098 & 0.026 & $<0.001$ & 1.103 & 1.049 & 1.160 \\
\hline STER & -0.053 & 0.016 & 0.001 & 0.949 & 0.920 & 0.978 \\
\hline Peak troponin-I & 0.047 & 0.016 & 0.003 & 1.048 & 1.016 & 1.082 \\
\hline TIMI-TG & -0.871 & 0.400 & 0.030 & 0.419 & 0.191 & 0.917 \\
\hline $\mathrm{MBG}_{\mathrm{pospCI}}$ & -2.340 & 0.456 & $<0.001$ & 0.096 & 0.039 & 0.236 \\
\hline IRA & -0.741 & 0.342 & 0.030 & 0.477 & 0.244 & 0.932 \\
\hline $\begin{array}{l}\text { Three coronary } \\
\text { disease }\end{array}$ & 3.882 & 1.076 & $<0.001$ & 48.534 & 5.895 & 399.592 \\
\hline
\end{tabular}

\begin{tabular}{lcccccc}
\hline \multicolumn{6}{c}{ Multivariate logistic regression analysis for the MinPWTpostPCI } \\
\hline MinPWT & 0.053 & 0.022 & 0.014 & 1.055 & 1.011 & 1.101 \\
STEsPCI & -0.065 & 0.015 & $<0.001$ & 0.937 & 0.911 & 0.965 \\
Peak troponin-I & 0.052 & 0.014 & $<0.001$ & 1.053 & 1.025 & 1.083 \\
TIMI-TG & -0.784 & 0.358 & 0.029 & 0.457 & 0.226 & 0.922 \\
MBG $_{\text {postPCI }}$ & -2.230 & 0.388 & $<0.001$ & 0.108 & 0.050 & 0.230 \\
IRA $_{\text {Three coronary }}$ & -858 & 0.319 & 0.007 & 0.427 & 0.227 & 0.792 \\
disease & 3.913 & 1.001 & $<0.001$ & 50.062 & 7.042 & 355.918 \\
\end{tabular}

\begin{tabular}{lcccccc}
\hline \multicolumn{7}{c}{ Multivariate logistic regression analysis for the PWD } \\
\hline PWD $_{\text {postPCI }}$ & 0.101 & 0.033 & 0.002 & 1.107 & 1.037 & 1.181 \\
STER & -0.062 & 0.015 & $<0.001$ & 0.939 & 0.912 & 0.968 \\
Peak troponin-I & 0.040 & 0.014 & 0.004 & 1.041 & 1.013 & 1.069 \\
TIMI-TG & -1.202 & 0.425 & 0.005 & 0.300 & 0.131 & 0.691 \\
MBG $_{\text {postPCI }}$ & -2.345 & 0.431 & $<0.001$ & 0.096 & 0.041 & 0.223 \\
IRA $_{\text {Three coronary }}$ & -0.795 & 0.325 & 0.014 & 0.452 & 0.239 & 0.854 \\
& 2.745 & 0.929 & 0.003 & 15.557 & 2.519 & 96.083
\end{tabular}

disease

SE: Standard error, $P$ : Significance (two-tailed), OR: Odds ratio, CI: Confident interval, MaxPWT: Maximum P-wave time, minPWT: Minimum P-wave time, post-PCI: Postpercutaneous coronary intervention, pre-PCI: Prepercutaneous coronary intervention, PWD: P-wave dispersion, MBG: Myocardial blush grade, TIMI-TG: Thrombolysis in acute myocardial infarction thrombus grade, STER: ST-elevation resolution, IRA: Infarct related artery

of ROS are as follows: (1) reducing conduction velocity through the activation of fibrotic processes by the assembly of connexin- 43 into gap junctions and the inhibition of the $\mathrm{Na}$ current through protein kinase $\mathrm{C}$ and c-Src kinase pathways; (2) causing repolarization abnormalities through $\mathrm{K}_{\mathrm{ATP}} I_{\mathrm{to}}, I_{\mathrm{Kr}}$, and $I_{\mathrm{Ks}}$ channel inhibition; (3) increasing intracellular $\mathrm{Ca}^{2+}$ through $\mathrm{Na}^{+} / \mathrm{Ca}^{2+}$ exchanger activation; (4) activation of a delayed $\mathrm{Na}^{+}$current; (5) impairment of sarco- or endoplasmic reticulum $\mathrm{Ca}^{2+}$-ATPase activity; and (6) facilitation of afterdepolarizations through ryanodine receptor effects (through CaMKII activation). ${ }^{[17-19]}$

PWD is characterized by a difference between the maximum and minimum P-wave durations on a surface ECG. ${ }^{[2]}$ 
Increased PWD reflects intra- and interatrial heterogeneity, which is associated with atrial arrhythmias, most notably atrial fibrillation, increased mortality, and morbidity. ${ }^{[15,25-30]}$ Andrikopoulos et al. ${ }^{[25]}$ found that PWD $>40 \mathrm{~ms}$ predicted idiopathic atrial fibrillation with an $83 \%$ sensitivity and $85 \%$ specificity. Aytemir et al. ${ }^{[26]}$ observed that a value of PWD greater than $36 \mathrm{~ms}$ was a good predictor of separating idiopathic paroxysmal atrial fibrillation and a healthy subject. Rosiak et al. ${ }^{[27]}$ led a study on patients with AMI using a signal-averaged electrocardiogram. The sensitivity and specificity of PWD $>25 \mathrm{~ms}$ and $\mathrm{PWT}>125 \mathrm{~ms}$ for predicting high-risk patient atrial fibrillation were $74 \%, 77 \%$ and $81 \%$, $82 \%$, respectively.

In literature, although we encountered some studies that found PWD and PWT as the predictors of atrial fibrillation, we did not find any study investigating the effects of the no-RF and RF on PWT and PWD. Since we found three studies assessing the effects of reperfusion therapy (PCI or thrombolytic therapy) on PWT and PWD, we compared the present results with them.

Akdemir et al. ${ }^{[9]}$ investigated the effects of PCI and thrombolytic therapy on PWD in two groups of patients who showed similar clinical characteristics, such as age, gender, left ventricular ejection fraction, cardiac risk factors, left atrial anteroposterior diameter and volume, and average symptom duration. The $\mathrm{PWD}_{\text {prePCI }}$ value was higher in both $\mathrm{PCI}$ and thrombolytic groups and did not show any statistical difference between them $(46 \pm 12 \mathrm{~ms}$ versus $57 \pm 8 \mathrm{~ms}$, $P>0.05$ ). Patients who experienced RF after PCI had normal values for $\mathrm{PWD}$, whereas the thrombolytic group continued to have higher values ( $31 \pm 13 \mathrm{~ms}$ vs. $55 \pm 5 \mathrm{~ms}, P=0.001)$.

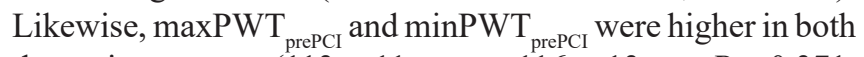
the patient groups $(113 \pm 11 \mathrm{~ms}$ vs. $116 \pm 13 \mathrm{~ms}, P=0.371$, and $66 \pm 10 \mathrm{~ms}$ vs. $60 \pm 12 \mathrm{~ms}, P=0.189$, respectively). After reperfusion therapy, $\operatorname{maxPWT}_{\text {postPII }}$ remained elevated in the thrombolytic group. The minPWT ${ }_{\text {postPCI }}$ did not exhibit any significant differences between the groups ( $68 \pm 12 \mathrm{~ms}$ vs. $61 \pm 9 \mathrm{~ms}, P=0.336$ ).

Khan et al ${ }^{[11]}$ studied PWD after 120 min of thrombolysis in two groups of patients who had more and $<70 \%$ of ST-segment resolution on their ECGs. PWD values for Group 1 ( $\geq 70 \%$ ST-segment resolution) and Group $2(<70 \%$ ST-segment resolution) decreased postthrombolytic therapy when compared to prethrombolytic values $(40.86 \pm 7.25$ vs. $48.97 \pm 10.72 \mathrm{~ms}$ and $47.91 \pm 6.14 \mathrm{~ms}$ vs. $51.59 \pm 8.34 \mathrm{~ms}$, respectively). Although the prethrombolytic PWD values did not exhibit any statistically significant differences between the two groups $(P=0.45)$, the postthrombolytic values $\operatorname{did}(P=0.001)$.

Karabag et al. ${ }^{[10]}$ investigated the relationship between the patency of IRA, STER, and PWD at 0, 30, 90, and $120 \mathrm{~min}$ of fibrinolysis. The PWD values at $0,30,90$, and $120 \mathrm{~min}$ were higher in patients without STER than those of patients with STER $(51.5 \pm 13.8 \mathrm{~ms}, 47.0 \pm 12.3 \mathrm{~ms}, 47.9 \pm 9.6 \mathrm{~ms}$,
$48.3 \pm 11.2 \mathrm{~ms}, 52.9 \pm 10.3 \mathrm{~ms}$, and $46.2 \pm 15.2 \mathrm{~ms}, 47.2 \pm 12.8$ $\mathrm{ms}, 46.5 \pm 14.5 \mathrm{~ms}, 43.9 \pm 13.3 \mathrm{~ms}$, and $44.8 \pm 11.5 \mathrm{~ms}$, respectively). Among these values, only the PWD value at 120 min exhibited statistical significance $(P<0.001)$. They additionally found almost similar results concerning the patency of the IRA. Patients with occluded IRA exhibited higher PWD values than patients with patent IRA $(49.1 \pm 14.7$ $\mathrm{ms}, 47.3 \pm 12.7 \mathrm{~ms}, 48.6 \pm 11.4 \mathrm{~ms}, 47.8 \pm 11.4 \mathrm{~ms}, 53.5 \pm 10.7$ $\mathrm{ms}$ and $47.9 \pm 14.9 \mathrm{~ms}, 46.9 \pm 12.4 \mathrm{~ms}, 45.3 \pm 14.0 \mathrm{~ms}$, $43.5 \pm 13.1 \mathrm{~ms}, 42.3 \pm 9.7 \mathrm{~ms}$, respectively), and only the PWD value at 120 min was statistically significant $(P=0.001)$.

The present results were compatible with the previous research. Pre-PCI values of maxPWT and PWD were elevated in both the groups without any statistical differences. After PCI, the RF group had statistically significantly lower values of maxPWT, minPWT, and PWD, suggesting a positive impact of RF on these values. Moreover, PWD and PWT had a negative correlation with \%STER and a positive correlation with SS, which is an indicator of coronary artery complexity.

\section{Conclusion}

In light of the literature data, thrombolytic or PCI therapy reduces the incidence of atrial arrhythmia in patients with AMI and the no-RF. Increases in PWT indices can cause an increased incidence of atrial arrhythmia. The results of this study showed that PCI has a more favorable effect on the decrease in PWT indices. Furthermore, our results suggest that $\mathrm{P}$-wave indices are simple electrocardiographic predictors that can differentiate between the no-RF and RF in AMI patients undergoing PCI.

\section{Financial support and sponsorship}

Nil.

\section{Conflicts of interest}

There are no conflicts of interest.

\section{RefEREnCes}

1. Harrison RW, Aggarwal A, Ou FS, Klein LW, Rumsfeld JS, Roe MT, et al. Incidence and outcomes of no-reflow phenomenon during percutaneous coronary intervention among patients with acute myocardial infarction. Am J Cardiol 2013;111:178-84.

2. Bouleti C, Mewton N, Germain S. The no-reflow phenomenon: State of the art. Arch Cardiovasc Dis 2015;108:661-74.

3. Durante A, Camici PG. Novel insights into an "old" phenomenon: The no reflow. Int J Cardiol 2015;187:273-80.

4. Rezkalla SH, Kloner RA. Coronary no-reflow phenomenon: From the experimental laboratory to the cardiac catheterization laboratory. Catheter Cardiovasc Interv 2008;72:950-7.

5. Congo KH, Belo A, Carvalho J, Neves D, Guerreiro R, Pais JA, et al. New-onset atrial fibrillation in ST-segment elevation myocardial infarction: Predictors and impact on therapy and mortality. Arq Bras Cardiol 2019;113:948-57.

6. Massó-van Roessel A, Escobar-Robledo LA, Dégano IR, Grau M, Sala J, Ramos R, et al. Analysis of the association between electrocardiographic P-wave characteristics and atrial fibrillation in the REGICOR study. Rev Esp Cardiol (Engl Ed) 2017;70:841-7.

7. Kimura-Medorima ST, Lino AP, Almeida MP, Figueiredo MJ, Silveira-Filho LD, de Oliveira PP, et al. P-wave duration is a predictor for long-term mortality in post-CABG patients. PLoS One 2018;13:e0199718. 
8. Kaykha A, Myers J, Desser KB, Laufer N, Froelicher VF. The prognostic importance of isolated P-Wave abnormalities. Clin Cardiol 2010;33:E87-93.

9. Akdemir R, Ozhan H, Gunduz H, Tamer A, Yazici M, Erbilen E, et al. Effect of reperfusion on $\mathrm{P}$-wave duration and $\mathrm{P}$-wave dispersion in acute myocardial infarction: Primary angioplasty versus thrombolytic therapy. Ann Noninvasive Electrocardiol 2005;10:35-40.

10. Karabag T, Dogan SM, Aydin M, Sayin MR, Buyukuysal C, Gudul NE, et al. The value of $\mathrm{P}$ wave dispersion in predicting reperfusion and infarct related artery patency in acute anterior myocardial infarction. Clin Invest Med 2012;35:E12-9.

11. Khan MH, Rahman A, Majumder AA, Rahman T, Haque M, Hussain KS, et al. Prediction of reperfusion and infarct-related artery patency after thrombolysis in acute anterior myocardial infarction by degree of $\mathrm{P}$ wave dispersion on ECG. Bangladesh heart J 2017;32:100-5.

12. van 't Hof AW, Liem A, Suryapranata H, Hoorntje JC, de Boer MJ, Zijlstra F. Angiographic assessment of myocardial reperfusion in patients treated with primary angioplasty for acute myocardial infarction: Myocardial blush grade. Zwolle Myocardial Infarction Study Group. Circulation 1998;97:2302-6.

13. Bazett HC. The time relations of the blood-pressure changes after excision of the adrenal glands, with some observations on blood volume changes. J Physiol 1920;53:320-39.

14. Kloner RA, Ganote CE, Jennings RB. The "no-reflow" phenomenon after temporary coronary occlusion in the dog. J Clin Invest 1974;54:1496-508.

15. Hickey MJ, Hurley JV, Morrison WA. Temporal and spatial relationship between no-reflow phenomenon and postischemic necrosis in skeletal muscle. Am J Physiol 1996;271:H1277-86.

16. Ray PD, Huang BW, Tsuji Y. Reactive oxygen species (ROS) homeostasis and redox regulation in cellular signaling. Cell Signal 2012;24:981-90.

17. Sovari AA. Cellular and molecular mechanisms of arrhythmia by oxidative stress. Cardiol Res Pract 2016;2016:9656078.

18. Pérez-Riera AR, de Abreu LC, Barbosa-Barros R, Grindler J, Fernandes-Cardoso A, Baranchuk A. P-wave dispersion: An update. Indian Pacing Electrophysiol J 2016;16:126-33.

19. González-Montero J, Brito R, Gajardo AI, Rodrigo R. Myocardial reperfusion injury and oxidative stress: Therapeutic opportunities.
World J Cardiol 2018;10:74-86.

20. Beresewicz A, Horackova M. Alterations in electrical and contractile behavior of isolated cardiomyocytes by hydrogen peroxide: Possible ionic mechanisms. J Mol Cell Cardiol 1991;23:899-918.

21. Ono N, Hayashi H, Kawase A, Lin SF, Li H, Weiss JN, et al. Spontaneous atrial fibrillation initiated by triggered activity near the pulmonary veins in aged rats subjected to glycolytic inhibition. Am J Physiol Heart Circ Physiol 2007;292:H639-48.

22. Azam MA, Zamiri N, Massé S, Kusha M, Lai PF, Nair GK, et al. Effects of late sodium current blockade on ventricular refibrillation in a rabbit model. Circ Arrhythm Electrophysiol 2017;10. pii: E004331.

23. Anderson ME. Oxidant stress promotes disease by activating CaMKII J Mol Cell Cardiol 2015;89:160-7.

24. Dilaveris PE, Gialafos JE. P-wave dispersion: A novel predictor of paroxysmal atrial fibrillation. Ann Noninvasive Electrocardiol 2001;6:159-65.

25. Andrikopoulos GK, Dilaveris PE, Richter DJ, Gialafos EJ, Synetos AG, Gialafos JE. Increased variance of $P$ wave duration on the electrocardiogram distinguishes patients with idiopathic paroxysmal atrial fibrillation. Pacing Clin Electrophysiol 2000;23:1127-32.

26. Aytemir K, Ozer N, Atalar E, Sade E, Aksöyek S, Ovünç K, et al. P wave dispersion on 12-lead electrocardiography in patients with paroxysmal atrial fibrillation. Pacing Clin Electrophysiol 2000;23:1109-12.

27. Rosiak M, Bolinska H, Ruta J. P wave dispersion and $P$ wave duration on SAECG in predicting atrial fibrillation in patients with acute myocardial infarction. Ann Noninvasive Electrocardiol 2002;7:363-8.

28. Magnani JW, Gorodeski EZ, Johnson VM, Sullivan LM, Hamburg NM, Benjamin EJ, et al. P wave duration is associated with cardiovascular and all-cause mortality outcomes: The National Health and Nutrition Examination Survey. Heart Rhythm 2011;8:93-100

29. Chen SC, Su HM, Huang JC, Chang K, Tsai YC, Chen LI, et al. Association of P-Wave Dispersion with Overall and Cardiovascular Mortality in Hemodialysis Patients. Am J Nephrol 2015;42:198-205.

30. Abdellah AT, El-Nagary M. Prevalence of $P$ wave dispersion and interatrial block in patients with systolic heart failure and their relationship with functional status, hospitalization and one year mortality. Egypt Heart J 2018;70:181-7. 